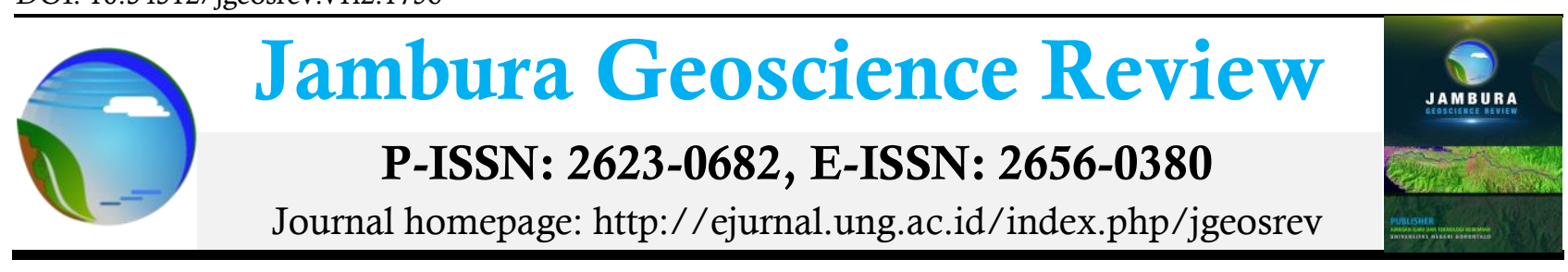

\title{
INTERAKSI SPASIAL KONDISI SOSIAL-EKONOMI TERHADAP KERAWANAN KEJAHATAN DI KOTA BANDUNG (STUDI KASUS SUMUR BANDUNG)
}

\author{
Moh. Dede ${ }^{\mathrm{a}}$, Dede Sugandi ${ }^{\mathrm{a}}$, Iwan Setiawan $^{\mathrm{a}}$ \\ a Departement Pendidikan Geografi, FPIPS, Universitas Pendidikan Indonesia, Jalan Dr. Setiabudhi no. 229, Bandung, Jawa \\ Barat, Indonesia (40154)
}

\section{INFO ARTIKEL}

\section{Status artikel:}

Diterima: 14 Desember 2018

Disetujui: 1 Juli 2019

Tersedia online: 9 Juli 2019

\section{Kata kunci:}

Crime risk;

Spatial interaction;

Sosio-economic conditions

Penulis korespondensi:

Moh. Dede

Universitas Pendidikan Indonesia,

Bandung, Indonesia

Email: desa96@student.upi.edu

\begin{abstract}
Crime is an unplanned change due to the process of urban development. The geographical approach is able to analyze spatial interactions of criminogenic factors into crime phenomenon. This study aims to explain the spatial interaction between socio-economic conditions and crime risk in Bandung City. The crime risk is obtained through Kernel Density Estimation (KDE) method based on The Annual Crime Data from Bandung Police Department, whereas the socio-economic condition data is revealed from interview and questioner with 176 respondents who determined by multistage random sampling in 37 hamlets. Variable interactions are analysed based on Geographically Weighted Regression (GWR) with Gaussian Distance Function type of cross validation as optimum weight. The results show the socio-economic conditions has a positive and significant effect on crime risk. This model shows that the independent variable acts as a crime attractor. Partially its known that economic conditions have a stronger interaction with crime risk than the social climate. The strongest interaction between variables are concentrated in the southern of Kebon Pisang Urban Village, precisely in the area passed by arterial roads at southern of Sumur Bandung. Crime prevention efforts are conducted using environmental interventions by the formal security personnels and strengthening the social climate of the community.
\end{abstract}

Copyright (C) 2019 JGeosREV-UNG This open access article is distributed under a Creative Commons Attribution (CC-BY) 4.0 International license

\section{Pendahuluan}

Kejahatan diartikan sebagai tindakan (perilaku) pelanggaran aturan hukum yang menimbulkan berbagai kerugian bagi manusia baik secara individu maupun kelompok, seperti kehilangan harta benda, munculnya rasa takut (trauma), bahkan menyebabkan hilangnya nyawa (Gosita, 2015). Tindak kejahatan didasari atas beragam motif yang erat kaitannya dengan aspek lingkungan dan psikis pelaku (Dede \& Widiawaty, 2017). Dalam satu dasawarsa terakhir jumlah kejahatan di Indonesia mengalami peningkatan sebanyak 17,97 persen dengan crime rate sebesar 140 (BPS, 2018). Kondisi ini menjadikan Indonesia berada pada posisi keempat dari sepuluh negara di Asia Tenggara perihal kerawanan kejahatan dengan aglomerasinya berada di kawasan perkotaan, seperti Jakarta, Surabaya, Medan, dan Bandung (Erizal, 2017).

Kota Bandung merupakan wilayah dengan angka tindak kejahatan tertinggi di Jawa Barat dengan kontribusi tahunannya mencapai 16 hingga 20 persen atas crime total pada tingkat provinsi, meskipun dari segi crime rate masih lebih rendah dari Kota Sukabumi dan Kota Cirebon. Sebagian besar kerawanan kejahatan di Kota Bandung memiliki pola spasial memusat pada bagian pusat dan barat yang mana kawasan ini dikenal sebagai wilayah pusat kegiatan atau CBD (Dede et al., 2017). Kejahatan dengan tipologi harta benda (property crime) yang meliputi pencurian kendaraan bermotor (curanmor), pencurian biasa (cubis), pencurian dengan pemberatan (curat), dan pencurian dengan 
kekerasan (curas) dominan terjadi yang menandakan perilaku kriminal dilatarbelakangi motif sosialekonomi sering terjadi (Satreskrim Polrestabes Bandung, 2018).

Di kawasan perkotaan, kausalitas kejahatan tidak dapat dilepaskan dari berbagai kondisi lingkungan urban yang berperan sebagai faktor pendorong (crime generator) maupun penarik (crime attractor) (Alam dan Ilyas, 2010). Pada kajian geography of crime, berbagai faktor kondisi lingkungan seperti penggunaan lahan, morfologi perkotaan, sosio-ekonomi, dan intervensi sosial dikenal sebagai criminogenic agents yang perlu dikaji agar tindakan pencegahan kejahatan berjalan efektif, karena tidak hanya mengacu pada tipologinya semata (Matthews, 2013; Heath, 2015). Bila dibandingkan dengan lingkungan fisik, criminogenic agent yang berasal dari lingkungan sosial terutama aspek sosio-ekonomi memainkan peranan yang lebih dinamis (Kusumah, 2017).

Motif ekonomi merupakan latar belakang utama individu untuk bertindak kejahatan. Menurut Bonger (2015), rendahnya kondisi ekonomi membuat seseorang putus asa dan memilih untuk menjadi pelaku kriminal, karena minimnya kesempatan mencari nafkah, terlebih bila keterampilan dan self control tidak dimilikinya. Di sisi lain, kondisi ekonomi yang tinggi dapat menjadi target sesuai (suitable targets) bagi pelaku karena tersedianya berbagai benda atau barang berharga, sehingga terjadilah property crime (Kitchen, 2015). Kondisi ekonomi yang berperan sebagai crime generator dan crime attractor dapat terjadi bila kesempatan untuk berbuat kejahatan tersedia. Mengacu pada teori determinisme ekonomi, kehidupan sosial umumnya sangat dipengaruhi oleh sistem ekonomi yang ada, sehingga kondisi ekonomi tidak dapat dilepaskan dari situasi sosialnya. Menurunnya intensitas dan kualitas hubungan sosial merupakan variabel dapat menjelaskan individu melakukan tindakan kejahatan baik secara langsung maupun criminogenic agent (Koentjoro, 2013).

Rendahnya intervensi terhadap lingkungan serta rendahnya kepedulian masyarakat perkotaan terhadap sekitarnya dapat memberikan peluang untuk terjadinya kejahatan, bahkan hal ini dapat bertambah bila suatu lingkungan tidak mempunyai keamanan dan kewaspadaan yang mumpuni (Drianda et al., 2015). Kejahatan terjadi karena adanya kesempatan dan niat pelaku yang dikuatkan oleh aspek sosial-ekonomi di lingkungan perkotaan merupakan fenomena menarik untuk dikaji dalam perspektif spasial, khususnya melalui geography of crime. Oleh sebab itu, penelitian ini bertujuan untuk mengetahui interaksi spasial kondisi sosial-ekonomi terhadap kerawanan kejahatan di Kota Bandung, khususnya Kecamatan Sumur Bandung yang memiliki tingkat kerawanan kejahatan tertinggi (crime total dan crime rate) sekaligus berperan sebagai CBD bagi kota ini. Analisis interaksi spasial dipilih karena berbagai data sosial-ekonomi tersebut bersifat kuantitatif yang memiliki keterkaitan dan heterogenitas spasial, serta berlaku secara lokal di tiap titik pengamatan (Nugroho \& Harmadi, 2015). Analisis interaksi spasial dapat diterima bila memiliki nilai yang lebih baik dari model konvensional (Mulyadi et al., 2019).

\section{Metodologi}

\subsection{Wilayah Kajian}

Penelitian ini dilakukan di Kecamatan Sumur Bandung, Kota Bandung, Provinsi Jawa Barat. Sumur Bandung terdiri atas 4 (empat) kelurahan yakni Braga, Babakan Ciamis, Kebon Pisang, serta Merdeka yang terbagi atas 37 rukun warga (RW). Secara geografis, wilayah ini terletak pada posisi $107^{\circ} 36^{\prime} 14,20^{\prime \prime} \mathrm{BT}-107^{\circ} 37^{\prime} 48,06^{\prime \prime}$ BT dan 6 $6^{\circ}$ ' 20,56” LS - 6 54'23,39” LS dengan luas mencapai 345,5 Ha. Berdasarkan sistem pusat pelayanan wilayah berhirarki Kota Bandung, Sumur Bandung berada pada wilayah Subpusat Pelayanan Kota (SPK) Sadang Serang dan Pusat Pelayanan Sub Wilayah Kota (SWK) Cibeunying.

Sumur Bandung memiliki penduduk sebanyak 35.572 jiwa dengan kepadatannya mencapai 101,27 jiwa/ha. Wilayah ini dikenal sebagai pusat Kota Bandung, karena berperan sebagai pusat pemerintahan, ekonomi, dan pariwisata yang dibuktikan dari banyaknya perkantoran, hotel, taman, dan pusat perbelanjaan. Dalam beberapa tahun terakhir, Sumur Bandung merupakan wilayah di Kota Bandung yang memiliki tingkat kerawanan kejahatan tertinggi dengan crime total 341 kasus dan crime rate 190,77 yang didominasi oleh kejahatan properti dan street crime (Satreskrim Polrestabes Bandung, 2018; Setiawan et. al., 2018).

\subsection{Data Penelitian}

Penelitian ini menggunakan dua sumber data, baik primer maupun sekunder. Data primer diperoleh hasil pengamatan, keusioner dan wawancara dengan 176 responden di Sumur Bandung yang terpilih berdasarkan formula Glenn D. Israel (Setiawan, et. al., 2018). Sementara itu, data sekunder diperoleh dari studi dokumentasi terhadap berbagai sumber resmi seperti Polrestabes Bandung, Polsek Sumur 


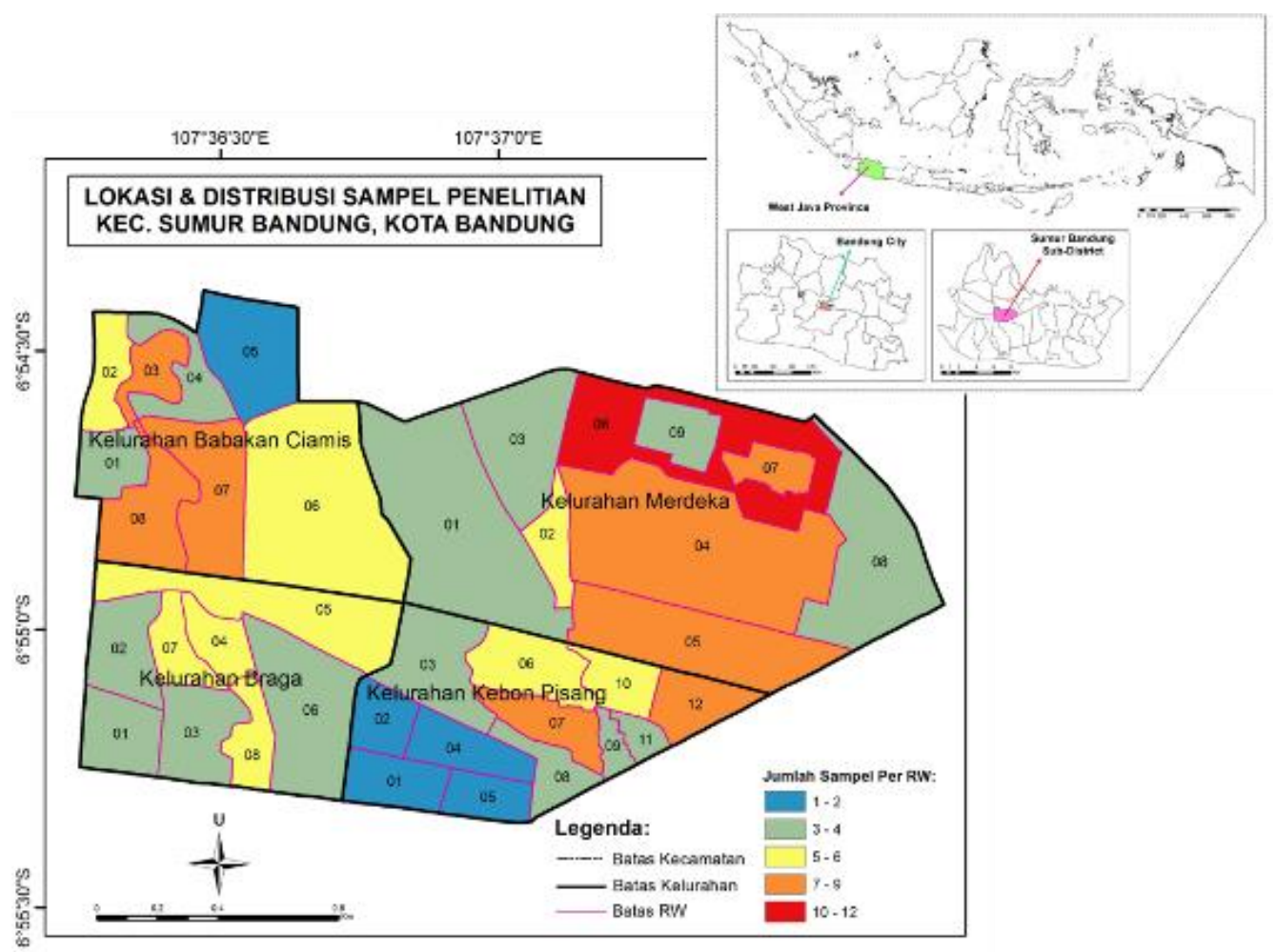

Gambar 1. Lokasi dan distribusi sampel penelitian

Bandung, Monografi Sumur Bandung, dan BPS Kota Bandung. Jumlah responden untuk tiap RW ditentukan dengan dan multistage random sampling.

Data sosial-ekonomi diperoleh dari penjabaran operasional dari beberapa parameter dari variabel iklim sosial dan kondisi ekonomi masyarakat yang diwakili oleh 176 kepala keluarga (KK) di Sumur Bandung melalui kegiatan pengisian kuesioner dan wawancara (lihat Gambar 1). Iklim sosial mampu mencegah individu untuk melakukan tindak kejahatan bila hubungan antar individu maupun lembagalembaga sosial yang ada berlangsung dengan baik (Hirschi, 2011). Dalam kajian kejahatan, iklim sosial dapat difokuskan pada parameter fear of crime (kecemasan terhadap kejahatan), social bond (rasa kebersamaan masyarakat), dan pengendalian sosial kejahatan (Kennedy, 2012). Sementara itu, kondisi ekonomi diartikan sebagai posisi individu maupun kelompok yang berkaitan dengan pemenuhan kebutuhan dan kepemilikan sejumlah objek yang dianggap berharga, sehingga terbagi atas rendah, sedang, serta tinggi (Koentjaraningrat, 2014). Menurut Fajriawati (2016), kondisi ekonomi masyarakat dapat diamati dari pendapatan, tanggungan, dan kepemilikan sumber daya. Oleh sebab itu, pengkajian kondisi ekonomi terhadap kejahatan diukur dari parameter pendapatan, besarnya pengeluaran, beban tanggungan, dan kepemilikan asset.

Berbeda dengan sosial-ekonomi, kerawanan kejahatan merupakan persebaran potensi terjadinya tindakan kejahatan yang akan menimpa seseorang atau kelompok pada suatu lokasi dan waktu tertentu (Fahmi, 2014). Pada penelitian ini kerawanan kejahatan diperoleh berdasarkan data laporan tahunan yang berasal dari Polrestabes Bandung dan Polsek Sumur Bandung pada tahun 2017. Data tersebut juga ditinjau kembali melalui kegiatan wawancara dengan sejumlah responden pada seluruh RW di Sumur Bandung. Data kejahatan umumnya dibagi dalam beberapa kategori berdasarkan arahan dari Kepolisian Republik Indonesia (Polri), meski begitu penelitian ini hanya berfokus pada blue collar crime yakni kejahatan yang dilakukan atas motif sosial-ekonomi dan dilakukan orang-orang biasa seperti tindakan pencurian, penjambretan, pencopetan, dan street crime lainnya (Galih, 2015). Dalam kajian spasial, lokasi tindak kejahatan (TKP) merupakan fokus utama dan dapat diolah lebih lanjut untuk menghasilkan informasi berupa crime hotspot. Data TKP kejahatan yang bersifat diskrit harus diubah agar sifatnya berubah menjadi kontinu dan memudahkan analisis interaksi spasial dengan variabel lain.

\subsection{Analisis Data}

Kondisi sosial-ekonomi merupakan faktor eksternal yang menyebabkan individu maupun kelompok untuk berbuat kejahatan, keduanya dapat menjadi faktor pendorong sekaligus penarik yang dapat dipelajari (Prayetno, 2013). Berbeda dengan penelitian tentang geography of crime di Kota Bandung yang menggunakan statistika konvensional untuk mengkaji interaksi antara kondisi lingkungan dan 
kejahatan, kajian ini berusaha untuk mengungkap interaksi spasial antara lingkungan yang diwakili oleh kondisi sosial-ekonomi dengan kerawanan kejahatan.

Kerawanan kejahatan diperoleh dari hasil analisis geostatistik menggunakan data kejahatan eksisting menggunakan Kernel Density Estimation (KDE), karena KDE dapat melakukan interpolasi dan menghasilkan distribusi spasial yang lebih baik dari line maupun point density. KDE juga mampu mengindentifikasi crime hotspot berdasarkan data kejahatan pada periode sebelumnya, karena tindak kejahatan pada waktu yang akan datang sering terjadi di sekitar lokasi sebelumnya (Dede et al., 2018). Pada penelitian ini, analisis KDE dilakukan dengan software QGIS dan divalidasi berdasarkan mean error (ME), root mean square error (RMSE), dan koefesien korelasi (R2) (Widiawaty et al., 2018). KDE dapat dilakukan dengan mengikuti metode Epanechnikov seperti pada Persamaan 1.

$$
\mathrm{K}=\frac{3}{4}\left(1-\mathrm{t}^{2}\right), \mathrm{t}=\frac{\mathrm{d}}{\mathrm{h}} \leq 1 \text { atau } \mathrm{K}=0, \mathrm{t}=\frac{\mathrm{d}}{\mathrm{h}}>1
$$

dimana $\mathrm{K}$ adalah nilai ekstrapolasi hasil $\mathrm{KDE}$, sedangkan $\mathrm{t}$ merupakan nilai densitas, $\mathrm{d}$ mewakili jarak antar titik dalam dataset spasial, dan $\mathrm{h}$ adalah nilai bandwith.

Guna mengetahui interaksi spasial kondisi sosial-ekonomi terhadap kerawanan kejahatan di Sumur Bandung, pemilihan metode harus didasari pada Hukum Geografi I bahwa segala sesuatu saling berinteraksi satu sama lain, tetapi kedekatan secara geografis akan memberikan interaksi lebih kuat dari berpengaruh daripada sesuatu yang lebih jauh (Rahmawati, dkk., 2015). Interaksi spasial ini lazim terjadi pada setiap data cross section yang memiliki heterogenitas. Pada penelitian ini, interaksi diantara dua fenomena tersebut dapat diketahui melalui analisis Geographically Weighted Regression (GWR) dengan menggunakan Persamaan 2.

$$
Y_{i}=\beta_{0}\left(u_{i}, v_{i}\right)+\beta_{k}\left(u_{i}, v_{i}\right) x_{i k}+\varepsilon_{i}
$$

dimana $Y_{i}$ adalah nilai observasi variabel terikat di lokasi ke- $i, u_{i} v_{i}$ yang menyatakan lokasi geografis fenomena i, $\beta_{0}\left(u_{i}, v_{i}\right)$ merupakan koefisien prediktor ke- $k$ untuk lokasi ke-i, dan $\varepsilon_{i}$ sebagai konstanta.

Peranan pembobot dan bandwith pada model GWR sangatlah penting. Pada penelitian ini, pembobot yang digunakan mengacu pada kriteria Gaussian Distance Function dengan bandwith optimum metode cross validation (CV). Kriteria ini memiliki kelebihan dari segi ketepatan model terhadap data, menghasilkan nilai bandwith optimum, nilai CV yang minimum (Marina \& Budiantara, 2013). Model interaksi ini dapat menunjukkan fenomena kerawanan kejahatan dipengaruhi oleh keberadaan kondisi

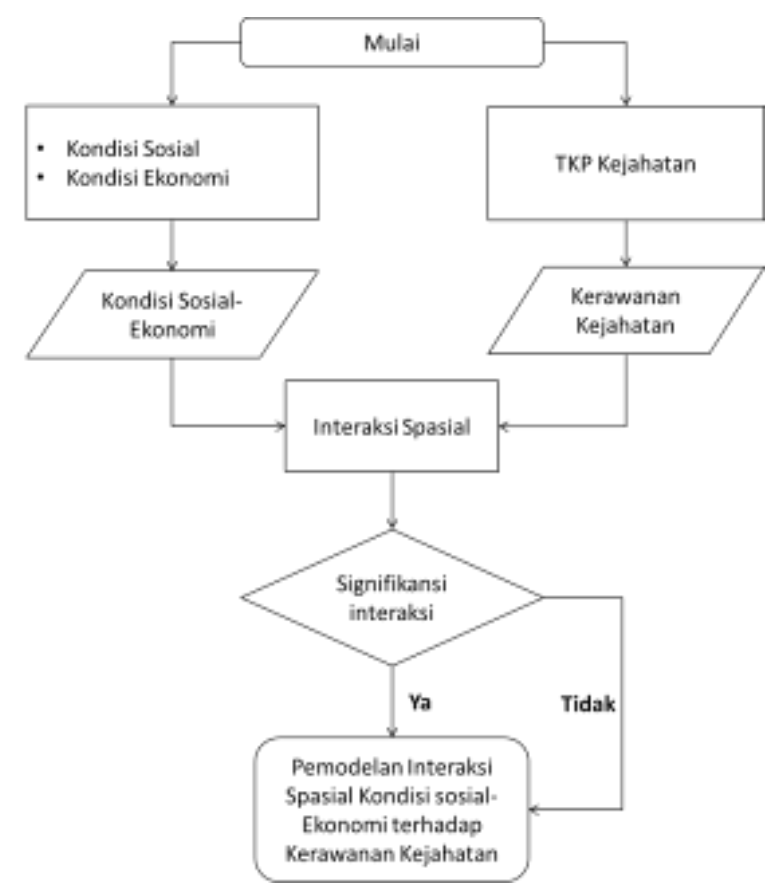

Gambar 2. Alur penelitian 
sosial-ekonomi pada wilayah secara geografis. Lebih jelasnya mengenai penelitian ini tersaji pada Gambar 2.

\section{Hasil dan Pembahasan}

\subsection{Kondisi Sosial-Ekonomi}

Salah satu penyusun variabel kondisi sosial-ekonomi pada kajian ini adalah iklim sosial. Mayoritas iklim sosial di Sumur Bandung dinyatakan moderat/sedang. Sebanyak $18 \mathrm{RW}$ dengan iklim sosial moderat terkonsentrasi di Kelurahan Merdeka dengan 7 RW, sedangkan 11 RW dengan kondisi sosial yang tinggi, sebagian besar berada di Kelurahan Babakan Ciamis dan Kelurahan Braga yang dikenal. Sementara itu, terdapat $7 \mathrm{RW}$ di wilayah ini yang memiliki iklim sosial rendah dengan sebarannya berada dekat dengan jalan arteri yang berperan sebagai pembatas antara Sumur Bandung dengan kecamatan lain (Gambar 3a). Hal ini disebabkan pemanfaatan ruang di sekitar jalan arteri umumnya berupa lahan komersial, dimana hubungan antara warga bersifat transaksional (Hapsari, 2011).

Iklim sosial di Sumur Bandung dominan dibentuk oleh parameter fear of crime dan social bond. Tingkat fear of crime masyarakat Sumur Bandung terbentuk akibat tindak kejahatan yang pernah terjadi di sekitarnya seperti pencurian maupun property crime lainnya. Bila mengacu pada Gambar $3 \mathrm{~b}$ terlihat bahwa sebagian besar fear of crime di wilayah ini berada pada level tinggi dan sangat tinggi. Fear of crime yang lebih tinggi ditemukan pada Kelurahan Babakan Ciamis dan Kelurahan Braga, terutama pada wilayah yang memiliki kepadatan penduduk yang tinggi. Meski begitu, tingkat fear of crime yang tinggi tidaklah berarti bila tidak memunculkan reaksi dan adaptasi masyarakat (Evans dan Herbert, 2014).

Pada parameter social bond diketahui bahwa hubungan antar masyarakat Sumur Bandung terjalin dengan baik. Tingkat social bond yang lebih tinggi ditemukan pada area yang relatif kecil serta memiliki populasi penduduk yang besar. Kondisi ini memperlihatkan kepadatan penduduk selaras dengan social bond di lingkungan sosialnya. Social Bond tertinggi dimiliki oleh penduduk yang tinggal di bagian barat Kelurahan Babakan Ciamis yang dikenal sebagai pemukiman padat penduduk. Gambar 3 juga menegaskan bahwa tingkat social bond di Kelurahan Merdeka lebih rendah dari kelurahan lainnya. Hal ini terjadi karena minimnya kesempatan bersosialisasi secara impersonal, karena sebagian besar warga di daerah tersebut bekerja pada sektor formal (Setiawan, et. al., 2018).

a) Fear of Crime

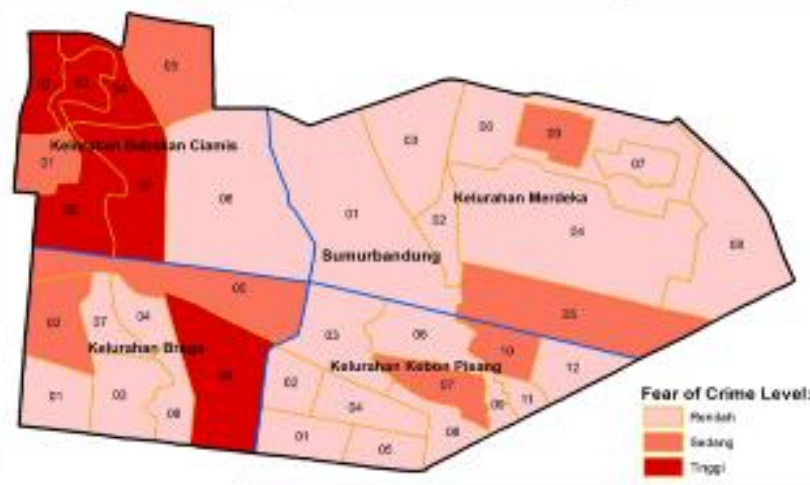

c) Pengendalian Sosial Kejahatan

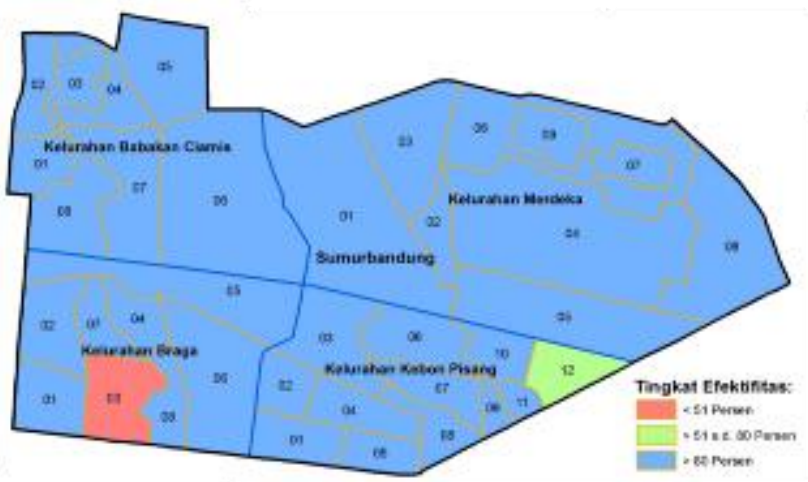

b) Social Bond

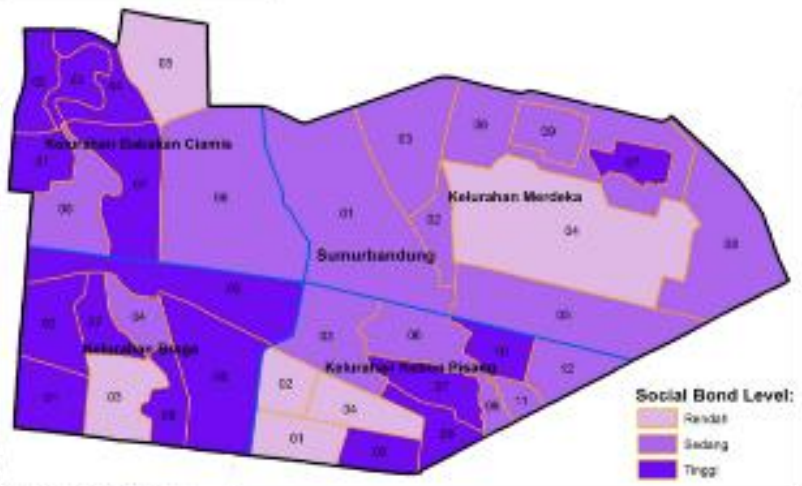

d) Iklim Sosial

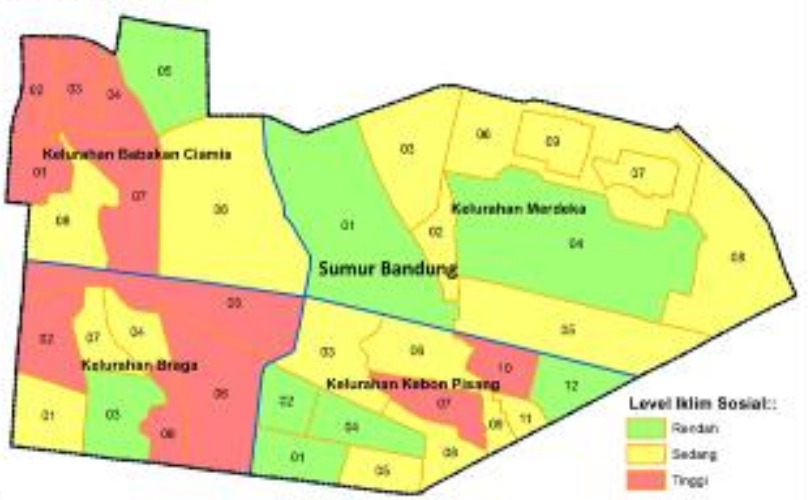

Gambar 3. Kondisi sosial di Sumur Bandung 
a) Jumlah Pendapatan

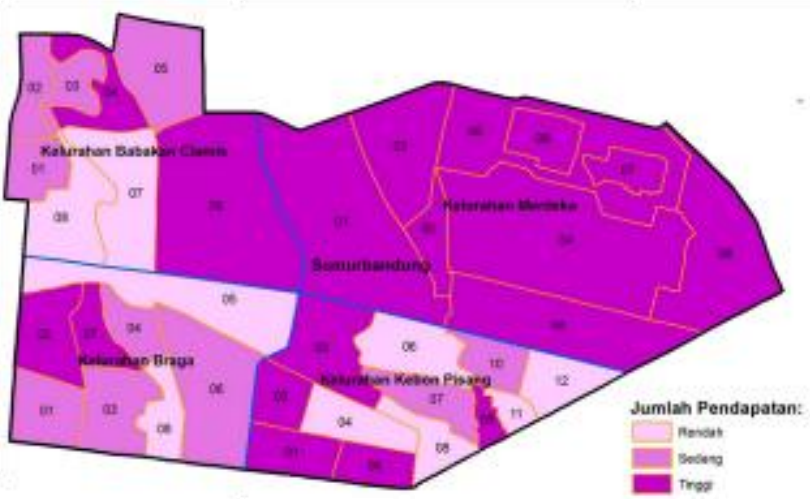

c) Kepemilikan Aset

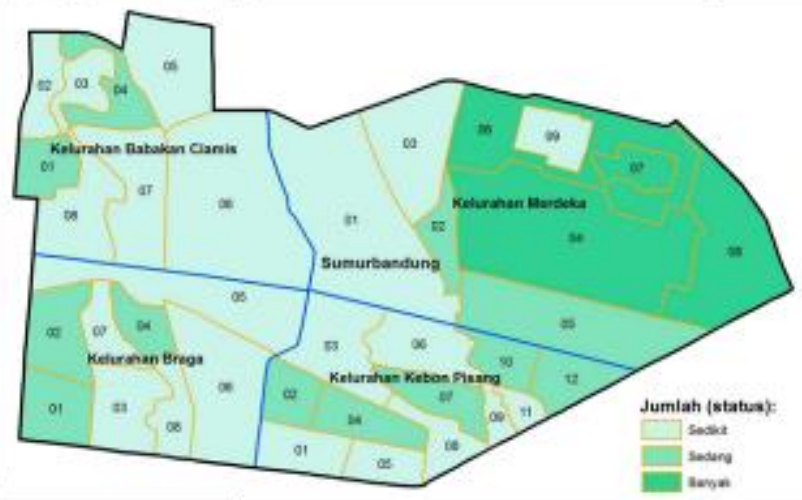

b) Beban Tanggungan

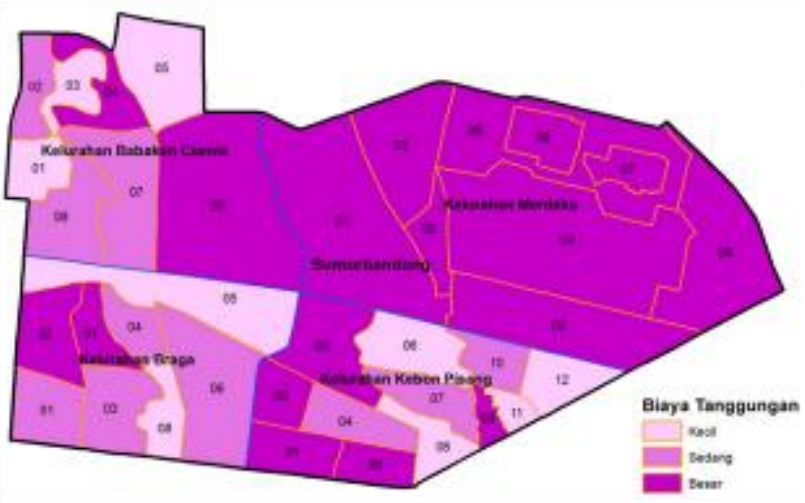

d) Kondisi Ekonomi

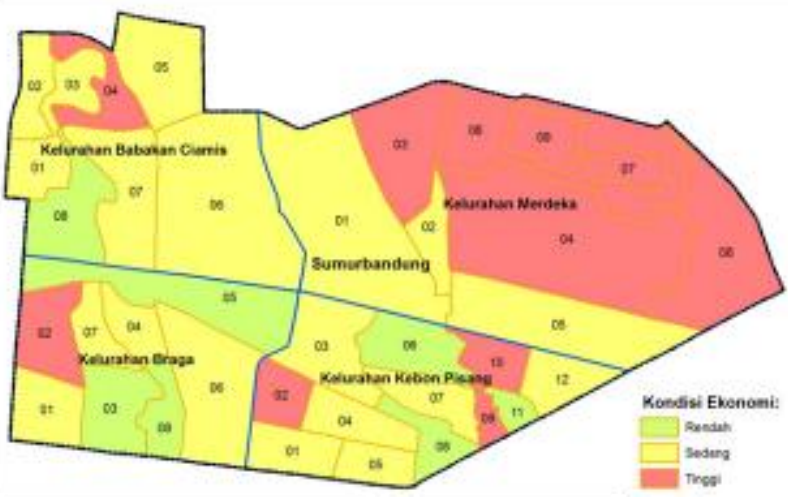

Gambar 4. Kondisi ekonomi di Sumur Bandung

Berbeda dengan fear of crime dan social bond yang memiliki level yang berbeda untuk tiap wilayah, pengendalian sosial kejahatan di Sumur Bandung mempunyai nilai yang hampir seragam. Upaya pengendalian sosial yang dimaksud menekankan pada upaya non formal yang dilakukan oleh masyarakat secara swadaya dan swakarsa dalam bentuk siskamling, linmas, maupun satpam pemukiman (Yani, 2015). Di Sumur Bandung upaya ini telah dilakukan di semua wilayah, meskipun terdapat beberapa RW yang efektivitasnya masih rendah. Iklim sosial pada tiap RW di Sumur Bandung umumnya berada pada tingkat menengah. Iklim sosial yang lebih tinggi / kuat berada pada bagian barat Sumur Banung. Gambar 3d menunjukkan wilayah dengan kepadatan penduduk yang rendah cenderung memiliki iklim sosial yang lebih rendah. Pola pemukiman yang berpagar juga turut menciptakan gated community, sehingga iklim sosial yang terbangun berbasis pada solidaritas organik (Widhyharto, 2009).

Kondisi ekonomi masyarakat yang diamati dari tingkat pendapatan, beban tanggungan, dan kepemilikan aset. Dari ketiga parameter tersebut diketahui bahwa masyarakat Sumur Bandung ratarata berada pada taraf ekonomi sedang, yakni mereka yang memiliki pendapatan antara Rp3.000.000,hingga Rp4.000.000,- dan memiliki kendaraan bermotor berjumlah satu atau dua unit per keluarga. Masyarakat Sumur Bandung dengan tingkat ekonomi sedang juga memiliki rasio income-outcome yang rendah, hal ini terbukti dari jumlah beban tanggungan (ekonomi) yang hanya mampu menyisakan sedikit pendapatan (Ismail \& Bakar, 2012).

Distribusi penghasilan masyarakat Sumur Bandung memiliki pola memusat, dimana golongan berpenghasilan tinggi berada di Kelurahan Merdeka dan sekitarnya (lihat Gambar 4a). Wilayah dengan pendapatan masyarakatnya yang tinggi, gejala gated community telah nampak seperti adanya pagar hunian, portal / gerbang untuk tiap entries, bahkan pos keamanan lingkungan (Hartanto, 2017). Kondisi seperti ini tidak dijumpai pada masyarakat dengan tingkat ekonomi rendah maupun sedang, karena memerlukan sejumlah biaya yang telah dikurangi beban tanggungan untuk tiap periode tertentu. Nilai beban tanggungan di tiap wilayah memiliki pola yang hampir serupa dengan jumlah pendapatan masyarakat. Hal tersebut menandakan bahwa tingkat konsumsi akan semakin meningkat tatkala pendapatan juga turut naik seperti yang ditunjukkan oleh Gambar $4 \mathrm{~b}$.

Bila jumlah pendapatan dan beban tanggungan memiliki pola yang hampir serupa, keadaan berbeda teramati pada kepemilikan aset berupa kendaraan bermotor yang mana distribusinya terpusat pada bagian timur Sumur Bandung (lihat Gambar 4c). Di wilayah ini rasio kepemilikan kendaraan bermotor 
Tabel 1. Uji validitas pemodelan kerawanan kejahatan

\begin{tabular}{llll}
\hline Tipe Reklasfifikasi & $\mathrm{ME}$ & $\mathrm{RMSE}$ & $\mathrm{R}^{2}$ \\
\hline Lima klasifikasi & $-0,75$ & 6,29 & 0,93 \\
Tiga klasifikasi & $-0,22$ & 1,26 & 0,96 \\
\hline Sumber: Hasil Penelitian, 2018. & & &
\end{tabular}

mencapai 8:2 yang berarti tiap 100 keluarga, 80 diantaranya memilikinya baik itu sepeda motor maupun mobil. Masyarakat menilai keberadaan kendaraan bermotor merupakan kebutuhan pokok bagi tiap keluarga guna menunjang mobilitas harian (Petersen, 2011).

Berdasarkan ketiga parameter tersebut diketahui bahwa sebanyak 54,05 persen masyarakat Sumur Bandung berada pada kondisi ekonomi level menengah, masyarakat dengan kondisi ekonomi yang tinggi berjumlah 29,73 persen dengan sebarannya dominan berada di Kelurahan Merdeka, selengkapnya tersaji pada Gambar 4d. Sementara itu, masyarakat kondisi ekonomi rendah di Sumur Bandung mencapai 16,22 persen, dimana jumlah ini mendekati presentasi rumah tangga miskin di Kota Bandung yang mencapai 17,76 persen (Aminah \& Istiqomah, 2018).

\subsection{Kerawanan Kejahatan}

Penentuan lokasi rawan tindak kejahatan kejahatan tergolong dalam crime mapping, karena menganalisis konsentrasi spasial kejahatan (crime hotspot) di wilayah tertentu secara kuantitatif. Guna memenuhi kaidah spatial continuous data dalam analisis regresi spasial, crime hotspot yang berasal dari data TKP kejahatan di Sumur Bandung diolah dengan KDE. Metode ini menghasilkan densitas kejahatan pada radius tertentu yang mencerminkan nilai kerawanan kejahatan di suatu wilayah (Gerber, 2014). Kerawanan kejahatan di Sumur Bandung yang terbagi menjadi tiga kelas yakni rendah, sedang, dan tinggi. Sebagai salah satu model geostatistik, hasil estimasi KDE yang baik harus memiliki nilai ME dan RMSE yang mendekati nol serta memiliki nilai korelasi $\left(\mathrm{R}^{2}\right)$ antara $\breve{Z}$ dan $Z$ yang tinggi, sehingga mampu mewakili real world (Johansson et al., 2015; Xiao, et al., 2016). Oleh sebab itu, reklasifikasi ini dipilih karena memiliki nilai validitas yang lebih baik dari hasil reclass lima kelas (lihat Tabel 1). Model ini menunjukkan pola konsentris kerawanan kejahatan di bagian timur Kelurahan Braga dan utara Kelurahan Babakan Ciamis yang dikenal sebagai area komersial utama bagi Kota Bandung seperti yang tersaji pada Gambar 5.

Kerawanan kejahatan di Sumur Bandung didominasi oleh wilayah dengan tingkat kerawanan kejahatan rendah (62,94 persen), kemudian disusul oleh wilayah dengan tingkat kerawanan kejahatan sedang $(30,50)$ dan tinggi $(6,85$ persen). Secara spasial, kerawanan kejahatan level sedang umumnya berada cukup dekat dengan wilayah kerawanan kejahatan tinggi. Fenomena ini menunjukkan bahwa kejahatan di wilayah ini cenderung berada di lokasi yang saling berdekatan satu sama lain secara spasial, serta sebaran suitable targets yang terbatas (Sherman, 1995). Di wilayah ini, suitable targets banyak dijumpai di jalanan, area komersial, dan fasilitas publik.

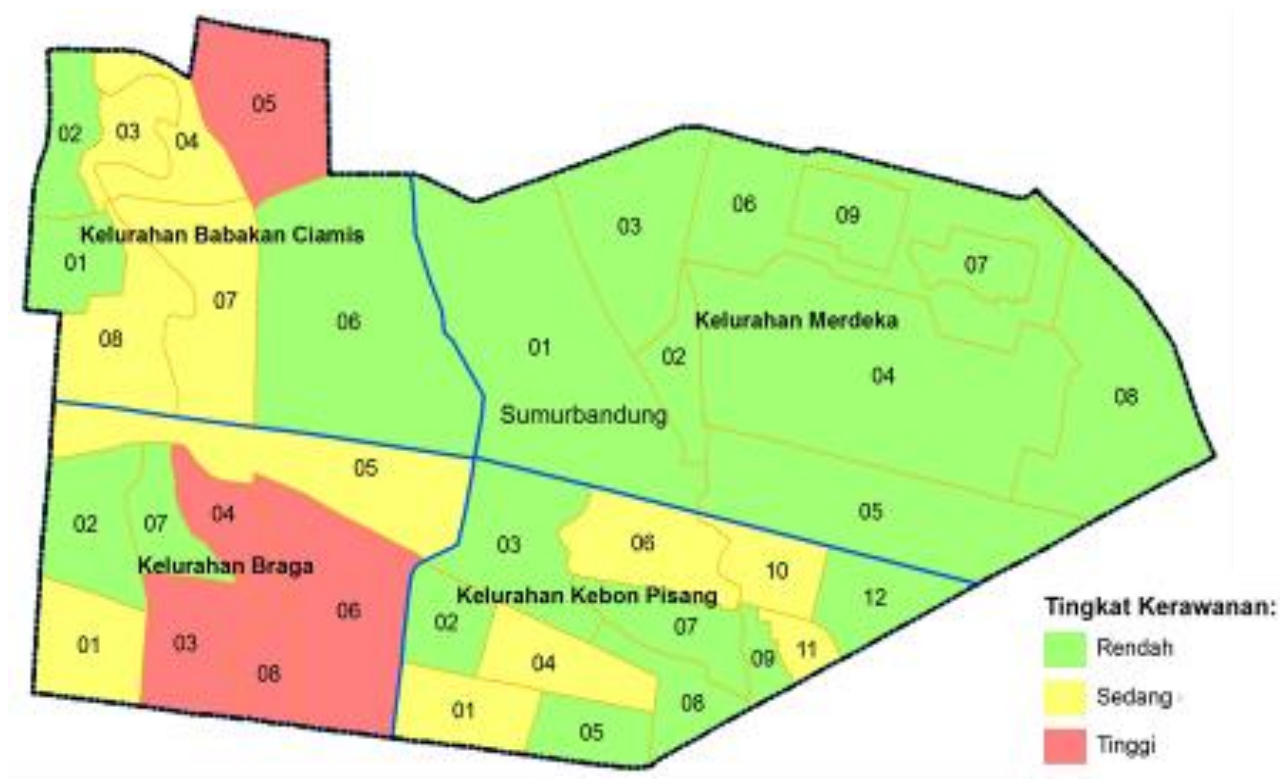

Gambar 5. Kerawanan Kejahatan di Sumur Bandung. 


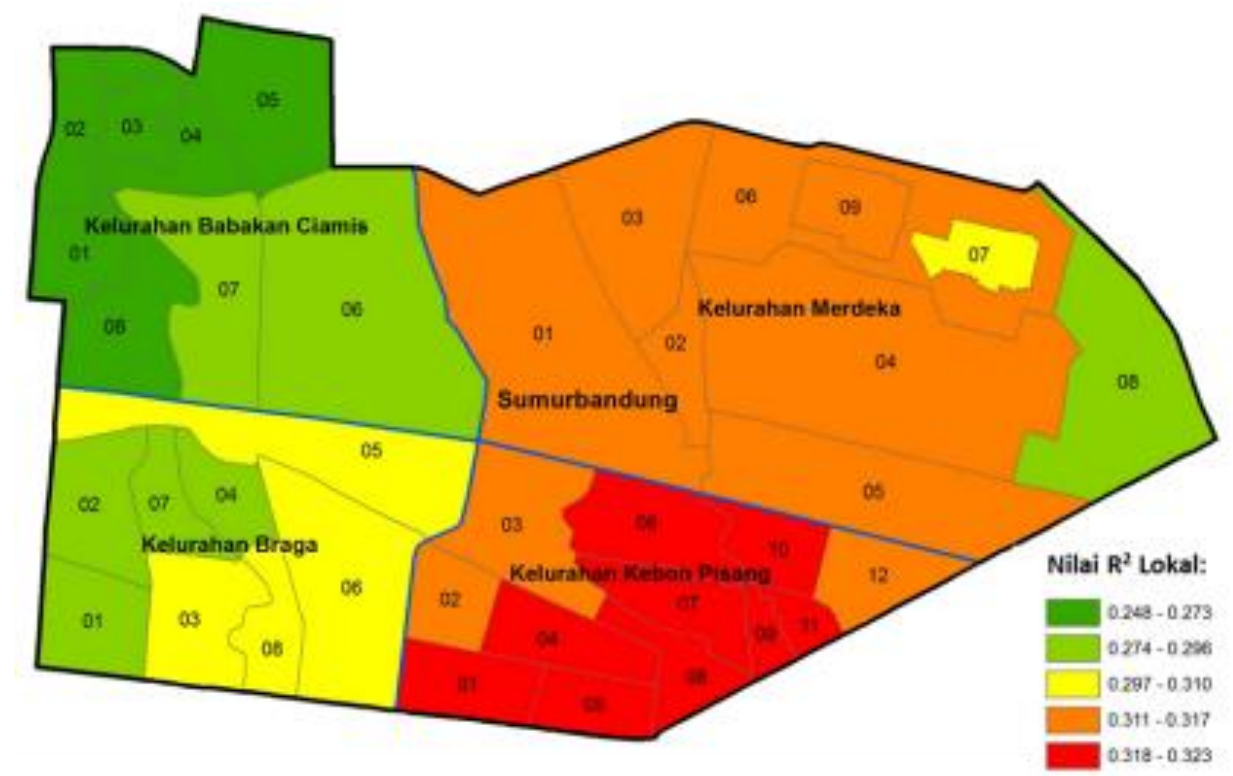

Gambar 6. Interaksi spasial kondisi sosial - ekonomi terhadap kerawanan kejahatan

\subsection{Interaksi Spasial Kondisi Sosial-Ekonomi Terhadap Kerawanan Kejahatan}

Kondisi sosial-ekonomi secara simultan memiliki pengaruh yang signifikan terhadap kerawanan kejahatan di Sumur Bandung. Interaksi spasial diantara keduanya mencapai 0,566 dengan taraf signifikansi satu persen dan efek determinasinya sebesar 32,01 persen. Nilai yang bersifat positif $r>0$ menandakan kondisi sosial - ekonomi di wilayah ini berperan sebagai crime attractor atau penarik tindak kejahatan (Lu \& Tang, 2011). Interaksi spasial antarvariabel memiliki iterasi sebesar 0,012 dan CV sebesar 180,99. Model ini juga memiliki ketepatan AICc sebesar 301,06 dan F hitung sebesar 7,44 dengan nilai residual regresi sebesar 5345,73 yang mana nilainya lebih rendah dari residual ordinary least square (OLS) yang mencapai 6076,72. Menurut Lestari (2015), model GWR dinyatakan valid bila nilai residual regresi lebih rendah dari OLS serta memiliki nilai $F$ hitung yang lebih tinggi dari $F$ tabel $(7,44>2,39)$. Dengan demikian, model GWR interaksi kondisi sosial - ekonomi terhadap kerawanan kejahatan dinyatakan valid seperti pada Persamaan 3.

$\mathrm{Y}_{\mathrm{i}}=0.265\left(\mathrm{X}_{\mathrm{i}}\right)-3.537\left(\mathrm{X}_{2}\right)+76.55$

Adanya konstanta sebesar 76,55 pada persamaan 3 menunjukkan adanya faktor lain yang lebih dominan terhadap kerawanan kejahatan di Sumur Bandung, seperti kondisi lingkungan fisik, faktor demografis, maupun niat dari pelaku kejahatan itu sendiri. Interaksi spasial antara kondisi sosial ekonomi terhadap kejahatan memiliki pola memusat serta dominan terjadi di Kelurahan Kebon Pisang, terutama pada beberapa wilayah yang dilintasi oleh jalan arteri seperti RW 01, RW 05, RW 07, RW 08, RW 09, dan RW 11 (lihat Gambar 6). Keberadaan jalan arteri membuat pemanfaatan ruang di sekitarnya menjadi area komersial yang diketahui memiliki kondisi ekonomi mumpuni, sekaligus bebas akses dan rendah pengawasan lingkungan oleh masyarakat (Anggraeni \& Sunaryo, 2015). Fenomena ini memperlihatkan wilayah yang berdekatan cenderung memiliki faktor criminogenic yang hampir serupa, sehingga turut mempengaruhi konsentrasi kerawanan kejahatan di Sumur Bandung. Informasi selengkapnya mengenai hasil penelitian ini tersaji secara secara daring (online) pada https://bit.ly/2UxgbFU.

\section{Kesimpulan}

Di Sumur Bandung, interaksi spasial kondisi sosial - ekonomi terhadap kerawanan kejahatan terjadi secara positif dan signifikan. Kondisi sosial - ekonomi berperan sebagai crime attractor yang memusat di bagian selatan Kelurahan Kebon Pisang. Model geographically weighted regression (GWR) menunjukkan kondisi ekonomi memiliki pengaruh parsial yang lebih tinggi dari pada iklim sosial. Oleh sebab itu, penguatan iklim sosial dapat terus dilakukan sebagai salah satu cara mencegah kejahatan di lingkungan sekitar. Kedepannya diharapkan terdapat kajian untuk mengetahui daya intervensi lingkungan secara 
formal oleh kepolisian terhadap kejahatan, karena ancaman keamanan dapat muncul akibat uncapable guardian.

\section{Ucapan Terima Kasih}

Penelitian ini didukung oleh Polrestabes Bandung (khususnya Satuan Reserse Kriminal dan Bagian Operasi) Polsek Sumur Bandung (Bapak Ade). Tak lupa pula kepada tim lapangan terutama M. A Widiawaty, Agus Anwar, Bayu Ansharim dan Sellina Aprilia yang berjasa tanpa lelah menemui responden. Selain itu, ucapan terima kasih juga ditujukkan kepada UPI dan pihak pengelola beasiswa Bidikmisi atas kesempatan empat tahun berkuliah bagi penulis.

\section{Referensi}

Alam, A. S. \& Ilyas, A. (2010). Pengantar Kriminologi. Makassar: Pustaka. Refleksi Books.

Aminah, A. N. \& Z. Istiqomah. (2018). 444 Ribu Jiwa di Kota Bandung Masuk Kategori Warga Miskin. Citing Internet sources URL https://www.republika.co.id/berita/nasional/daerah/ 18/03/30/p6dok5384-444-ribu-jiwa-di-kota-bandung-masuk-kategori-warga-miskin.

Anggraeni, N. \& Sunaryo, B. (2015). Hubungan perubahan fisik ruang dengan kondisi sosial ekonomi masyarakat di kawasan koridor aglomerasi Mertoyudan, Kabupaten Magelang. Jurnal Wilayah dan Lingkungan, 3 (2): 79 - 94.

Bonger, W. A. (2015). An Introduction to Criminology.London: Routledge.

BPS. (2018). Statistik Kriminal 2018. Jakarta: Sub Direktorat Statistik Politik dan Keamanan, Badan Pusat Statistik.

Dede, M. \& Widiawaty, M. A. (2017). Mewujudkan Pemanfaatan Sistem Informasi Geografis untuk Pencegahan Kriminalitas di Indonesia. Citing Internet sources URL https://osf.io/preprints/inarxiv/hx3mf/.

Dede, M., Setiawan, I., \& Mulyadi, A. (2017). Application GIS to analyse crime risk in Bandung. In Proceedings of The $2^{\text {nd }}$ International Conference of Sociology Education, 4 October 2017. Bandung. Stubal: Scitepress. doi 10.5220/0007102605970602.

Dede, M., Sugandi, D., \& Setiawan, I. (2018). Pengaruh kondisi lingkungan terhadap kerawanan kejahatan di kawasan perkotaan (studi kasus di Kecamatan Sumur Bandung, Kota Bandung)". An article of Seminar Nasional Geomatika 2018: Penggunaan dan Pengembangan Produk Informasi Geospasial Mendukung Daya Saing Nasional, 5 - 6 October 2018. Bogor: Badan Informasi Geospasial.

Drianda, R. P., I. Kinoshita, \& Deviana, F. (2015). Perencanaan lingkungan perkotaan yang aman dari ancaman kriminalitas terhadap anak: sebuah studi kasus dari negeri Jepang. Jurnal Perencanaan Wilayah dan Kota, 26 (1), 7 - 17.

Erizal, M. E. (2017). Analisis faktor-faktor yang mempengaruhi 'crime rate' di Indonesia tahun 20112015. Master Thesis, Fakultas Ekonomi, Universitas Andalas.

Galih, Y. S. (2015). Kejahatan tingkat tinggi. Jurnal Ilmiah Galuh Justisi, 3 (2): 257 - 270.

Gerber, M. S. (2014). Predicting crime using twitter and kernel density estimation. Decision Support Systems, 61: $115-125$.

Gosita, A. (2015). Masalah Korban dan Kejahatan. Jakarta: Penerbit Universitas Trisakti.

Hapsari, H. D. (2011). Kaitan pola neighbourhood pada interaksi sosial penghuni. Undergraduated Thesis, Fakultas Teknik, Universitas Indonesia.

Hartanto, T. (2017). Gated Community: Studi Kasus: Perumahan Casa Grande di Yogyakarta. Citing Internet sources URL https://media.neliti.com/media/publications/141836-ID-gatedcommunity-studi-kasus-perumahan-ca.pdf.

Heath, R. (2015). RGS Innovative Teaching Grant Resources - Investigating The Geography of Crime. Royal Geographical Society. London.

Hirschi, T. (2011). Causes of Delinquency. New Jersey: Transaction Publishers.

Ismail, R. \& Bakar, N. T. A. (2012). The relationship between income, expenditure and household savings in peninsular malaysia. Malaysian Journal of Consumer and Family Economics, 15 (1): $168-189$.

Johansson, E., Gåhlin, C., \& Borg, A. (2015). Crime hotspots: an evaluation of the KDE spatial mapping technique. In Proceeding of the 2015 European Intelligence and Security Informatics Conference, Manchester, UK. Manchester: IEEE. 
Kennedy, D. M. (2012). Deterrence and Crime Prevention: Reconsidering the Prospect of Sanction. New Jersey: Routledge.

Kitchen, P. (2015). Exploring the Link between Crime and Socio-Economic Status in Ottawa and Saskatoon: A Small-Area Geographical Analysis. Ottawa: Department of Justice Canada, Research and Statistics Division.

Koentjoro. (2013). Kriminologi dalam Perspektif Psikologi Sosial. Yogyakarta: Universitas Negeri Yogyakarta.

Kusumah, M. W. (2017). Peta kejahatan di Indonesia. Jurnal Hukum dan Pembangunan, 19 (4): 333 338.

Lestari, W. S., Pawitan, G. \& Jaya, M. (2015). Analisis Data Spasial Menggunakan Metode Geographically Weighted Regression (Studi Kasus Data PDRB per Kapita di Provinsi Jawa Timur). Citing Internet sources URL http://pustaka.unpad.ac.id/wpcontent/uploads/2015/01/paper-Semnas-Wahyu-Sri-estari.pdf.

Lu, J. \& Tang, G. (2011). The spatial distribution cause analysis of theft crime rate based on GWR Model. In Proceeding of The 2011 International Conference on Multimedia Technology. Hangzhou: IEEE.

Marina, S. M. T. \& Budiantara, I. N. (2013). Pemodelan faktor-faktor yang mempengaruhi persentase kriminalitas di Jawa Timur dengan pendekatan regresi semiparametrik spline. Jurnal Sains dan Seni Pomits, 2 (2): 2337 - 3520.

Matthews, S. (2013). Geoprofiling crime: engaging students with lessons from applied geography. In Proceeding of $A G T A 2013$ Perth Geography's New Frontier, 7 - 10 January 2013. Perth: AGTA.

Mulyadi, A., Dede, M. \& Widiawaty, M. A. (2019). Spatial interaction of groundwater and surface topographic using geographically weighted regression in built-up area. An article in Sustainable Urban Water International Seminar 24 January 2019, Bogor, Indonesia. Bogor: IOP Publishing.

Nugroho, A. H. \& Harmadi, S. H. B. (2015). Analisis spasial kriminalitas harta benda di wilayah Jadetabek. Jurnal Ekonomi dan Pembangunan Indonesia. 15 (2): 158 - 172.

Petersen, R. (2011). Transportasi berkelanjutan: panduan bagi pembuat kebijakan di kota-kota berkembang. Perencanaan Tata Ruang Kota dan Transportasi Perkotaan. Eschborn: Deutsche Gesellschaft für Internationale Zusammenarbeit (GIZ) GmbH.

Prayetno. (2013). Kausalitas kemiskinan terhadap perbuatan kriminal (pencurian). Media Komunikasi FIS, 12 (1): $30-45$.

Rahmawati, R., Safitri, D., \& Fairuzdhiya, O. U. (2015). Analisis spasial pengaruh tingkat pengangguran terhadap kemiskinan di Indonesia (studi kasus Provinsi Jawa Tengah). Media Statistika, 8 (1): 23 - 30.

Satreskrim Polrestabes Bandung. (2018). Data Tindak Pidana Tahun 2017. Bandung: Polrestabes Bandung.

Setiawan, I., Dede, M., Sugandi, D. \& Widiawaty, M. A. (2018). Investigating urban crime pattern and accessibility using geographic information system in Bandung City. In Proceeding of The $5^{\text {th }}$ International Seminar on Tropical Eco Settlements (ISTECS) 2018, 14 $4^{\text {th }}-15^{\text {th }}$ November 2018 Bali, Indonesia. Dubai: Knowledge-E.

Sherman, L. W. (1995). Hot spots of crime and criminal careers of places. Crime and Place: Crime Prevention Studies 4. Missouri: Willow Tree Press.

Weisburd, D. (2018). Hot spots of crime and place-based prevention. Criminology \& Public Policy, 17 (1): $5-25$.

Widhyharto, D. S. (2009). Komunitas berpagar antara inovasi sosial dan ketegangan sosial (studi kasus di komunitas berpagar di D.I. Yogyakarta, Indonesia. Jurnal Ilmu Sosial dan Ilmu Politik, 13 (2): $204-230$.

Widiawaty, M., Dede, M., \& Ismail, A. (2018). "Kajian Komparatif Pemodelan Air Tanah Menggunakan Sistem Informasi Geografis di Desa Kayuambon, Kabupaten Bandung Barat". Jurnal Geografi Gea, 18 (1): 63 - 71.

Xiao, Y., Gu, X, Yin, S., Shao, C., Cui, Y., Zhang, Q., \& Niu, Y. (2016). Geostatistical interpolation model selection based on ArcGIS and spatio-temporal variability analysis of groundwater level in Piedmont Plains, Northwest China. Journal SpringerPlus, 5 (425): 2 - 15.

Yani, M. M. (2015). Pengendalian sosial kejahatan: suatu tinjauan terhadap masalah penghukuman dalam perspektif sosiologi. Jurnal Cita Hukum, 2 (1), 76 - 9. 